\title{
Pancreatico-gastric anastomotic insufficiency successfully treated with endoscopic vacuum therapy
}

We carried out an adapted Kausch-Whipple operation with gastro-pancreatic anastomosis in a 65-year-old male patient with duodenal adenocarcinoma (pT3, pN0, M0, R0). On postoperative day 2 we observed substantial discharge of air and biliary fluid from the perianastomotic drain. Initial endoscopy showed a semicircular dehiscence of the pancreaticogastric anastomosis ( $\mathbf{F i g} \mathbf{1}$ ). The postpyloric anastomosis was intact. There was no general abdominal guarding in the spontaneously breathing and hemodynamically stable patient.

An intraluminal vacuum drainage system ( Fig. 2) constructed from a long openpore polyurethane foam (length $12 \mathrm{~cm}$ and diameter $2 \mathrm{~cm}$ ) and a gastric tube (B. Braun Endo-SPONGE, Melsungen, Germany; Ventrol, $14 \mathrm{Ch} \times 120 \mathrm{~cm}$, Covidien, Dublin, Ireland) was placed over the anastomosis. We have described the procedure in previous publications [1]. Applying a continuous negative pressure of $125 \mathrm{mmHg}$ (V.A.C. Freedom, Kinetic Concepts, Inc. San Antonio, Texas, USA) resulted in the intended collapse of the stomach around the vacuum drainage system and complete evacuation of all digestive fluids ( $\bullet$ Fig.3).

After placement of drainage system, biliary discharge from postoperative drain decreased as did the levels of inflammatory parameters. The patient was on parenteral nutrition but was allowed to drink water. A follow-up endoscopy 4 days after the procedure revealed the anastomotic dehiscence had reduced in size and no discharge of air into the perianastomotic drain. The stomach had completely collapsed around the intraluminal vacuum drainage. The mucosa showed the typical erosion pattern ( Fig.4) and swift evacuation of the flushing fluid was indicative of normal function of the vacuum drainage, which was thus left in place. On day 8 there were no endoscopic signs of anastomotic leakage and vacuum therapy was terminated. Additional conventional contrast imaging did not show signs of

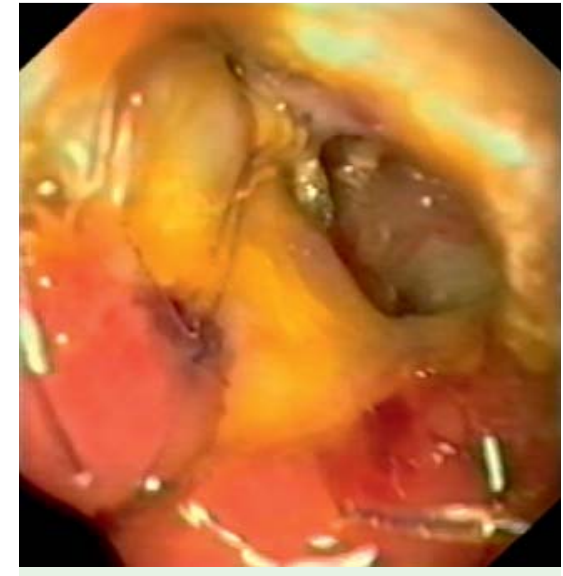

Fig. 1 Anterior aspect of pancreatico-gastric anastomotic leakage in a 65-year-old man with duodenal adenocarcinoma treated with an adapted Kausch-Whipple operation with gastro-pancreatic anastomosis.

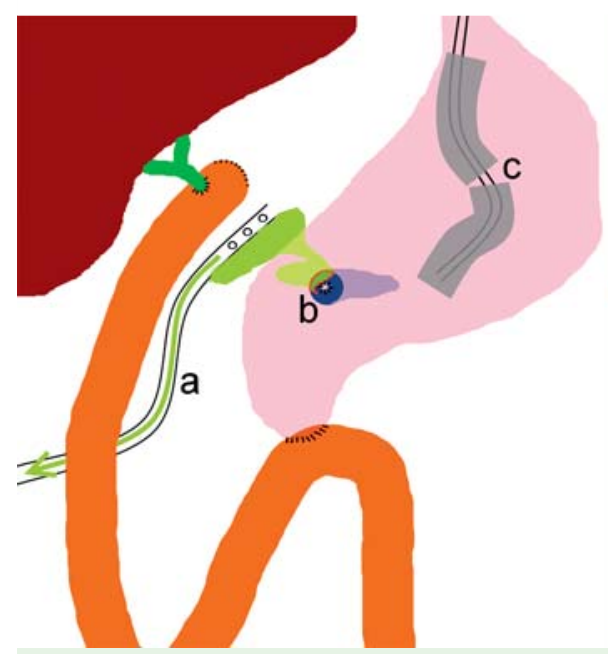

Fig.3 a Perianastomotic drain with discharge of air and digestive fluids. b Leakage from the pancreatico-gastric anastomosis. c Vacuum drainage system. d Application of negative pressure and collapse of the stomach around the vacuum drainage. e The gastro-jejunostomy. $\mathrm{f}$ The biliodigestive anastomosis.

leakage and the patient was switched to full liquid oral nutrition. Follow-up endoscopy 3 and 7 days after therapy

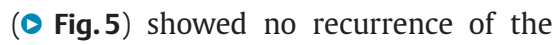
anastomotic dehiscence. The patient was put on full oral nutrition and the perianastomotic drain was removed. Another follow-up endoscopy of the asymptomatic
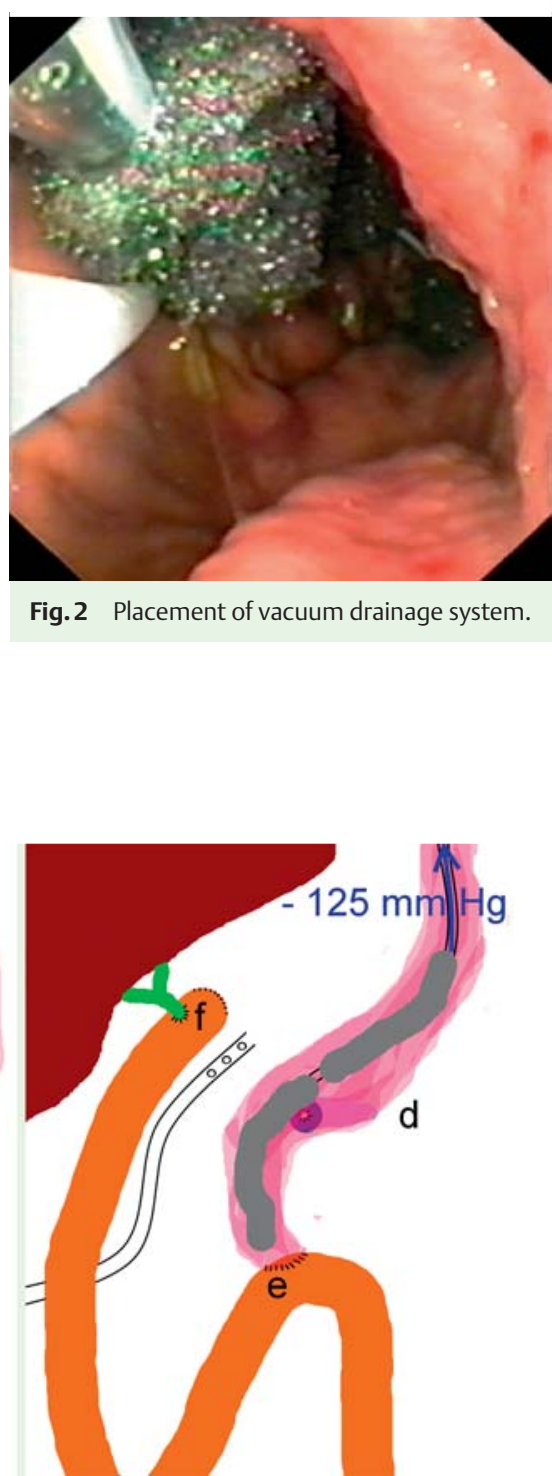

Fig.2 Placement of vacuum drainage system.

patient 75 days after therapy revealed normal postoperative condition.

Endoscopy_UCTN_Code_TTT_1AO_2AI

Competing interests: None 

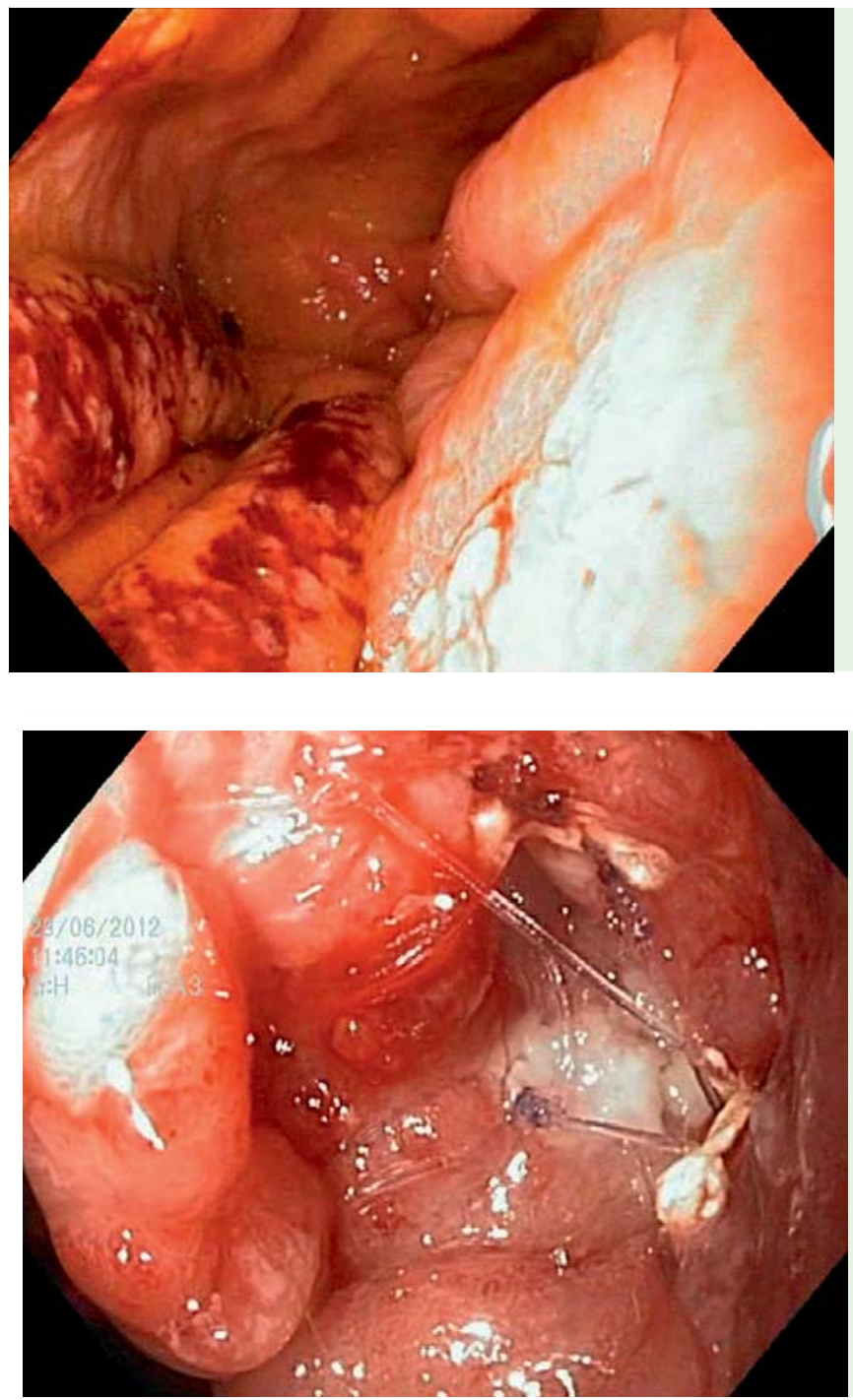

Fig.4 Mucosal erosion pattern after removal of vacuum drainage system on day 8.

\section{T. Schorsch, C. Müller, G. Loske}

Department for General, Abdominal, Thoracic and Vascular Surgery, Katholisches Marienkrankenhaus, Hamburg, Germany

\section{Reference}

1 Loske GSTMC. Intraluminal and intracavitary vacuum therapy for esophageal leakage: a new endoscopic minimally invasive approach. Endoscopy 2011; 43: 540-544

\section{Bibliography}

Dol http://dx.doi.org/

10.1055/s-0032-1326260

Endoscopy 2013; 45: E141-E142

(c) Georg Thieme Verlag KG

Stuttgart · New York

ISSN 0013-726X

Fig. 5 Pancreaticogastric anastomosis with no signs of leakage 3 days after vacuum therapy.

\section{Corresponding author}

\section{G. Loske}

Department for General, Abdominal,

Thoracic and Vascular Surgery

Katholisches Marienkrankenhaus Hamburg GmbH

Alfredstrasse 9

22087 Hamburg

Germany

Fax: +49-40-25461400

loske.chir@marienkrankenhaus.org 